\title{
The Great Comet of 1577: a Palestinian observation
}

\author{
Sam M. Silverman and Eran Limor \\ 18 Ingleside Road, Lexington, MA 02420, USA \\ Correspondence: Eran Limor (eranhlimor@gmail.com)
}

Received: 3 March 2021 - Revised: 12 April 2021 - Accepted: 12 April 2021 - Published: 9 June 2021

\begin{abstract}
C/1577 V1 was one of the brightest comets and one of the few early observed twin-tail comets. This paper presents the historical and cultural background for the observation of the comet from Safed, Palestine (1577).
\end{abstract}

\section{Introduction}

The Great Comet of 1577, namely C/1577 V1, was intrinsically bright, perhaps even the second brightest, in the past 500 years (Kronk, 1999). This comet is also significantly important in terms of the history of astronomy, as this comet allowed Tycho Brahe to locate comets and other astronomical objects above the terrestrial atmosphere (see, e.g., Hellman, 1944; Christianson, 1979; Schechner Genuth, 1997; Van Nouhuys, 1998; Granada, 2006; Silverman, 2008; Hayakawa et al., 2021). Observations of the comet were made on 2 November in Peru (possibly); 4 and 6 November in Mexico; 8 November in Japan; 9 November in the Baltic Sea, and at many sites from 10 November on in Europe; from 14 November in China; and somewhere around mid-November in Korea (Kronk, 1999).

The comet was also observed at Safed in Palestine $\left(32^{\circ} 58^{\prime} \mathrm{N}, 35^{\circ} 30^{\prime} \mathrm{E}\right)$ (Silverman, 2008). It is one of a small group of early observations of double-tailed comets, which have recently become of interest where one of the tails has been interpreted as due to the plasma tail (e.g., Hayakawa et al., 2017, 2021; Zolotova et al., 2018). Developing from Silverman (2008), this paper presents the historical and cultural context of the Palestinian observation of the Great Comet of 1577 (C/1577 V1).

\section{Historical record}

Chaim Vital (11 October 1542-24 April 1620) compiled a collection of his and others' dreams and omens, in The Book of Visions (Faierstein, 1999). Here, he describes this comet as follows:
Rosh Hodesh, Kislev, 5338, after sunset ${ }^{1}$, a large star with a long tail, pointing upward, was seen in the southwestern part of the sky. Part of the tail was also pointing eastward. It lingered there for three hours. Then it sank in the west behind the hills of Safed. This continued for more than fifty nights (Faierstein, 1999:95; Silverman, 2008:123).

Here, the original date is described in the Jewish calendar as the first of Kislev in the Jewish year 5338. This date is converted to 11 November 1577 in the Julian calendar. Its occurrence was originally translated as "after sunrise" in Faierstein (1999:95) but corrected to "after sunset" (Silverman, 2008:123). As Jewish days run from sunsets to sunsets, this observation was made on the evening of 10 November. Its appearance in the southwestern part of the sky is consistent with Thomas Twyne's observation in England on 10 November, who also noted it as appearing in the southwest part of the heavens (Hellman, 1944:287).

Apart from Cornelius Gemma (Silverman, 2008; Hayakawa et al., 2021), European observers on the whole speak only of a tail, in contrast to Vital's description of a double tail. This is perhaps consistent with Tycho's description of a very long tail, somewhat bent in the middle. The description of a double tail is similar to, and consistent with, one tail being ions with motion determined by the solar wind, the other being dust impelled by radiation pressure. For comparison see the photo of the double tail in Comet Hale-Bopp (Fig. 1).

\footnotetext{
${ }^{1}$ The printed version here says "before sunset". In a personal communication with the translator, on rechecking this point, he states that this should be "after sunset" and that the correction will appear in any subsequent editions.
} 


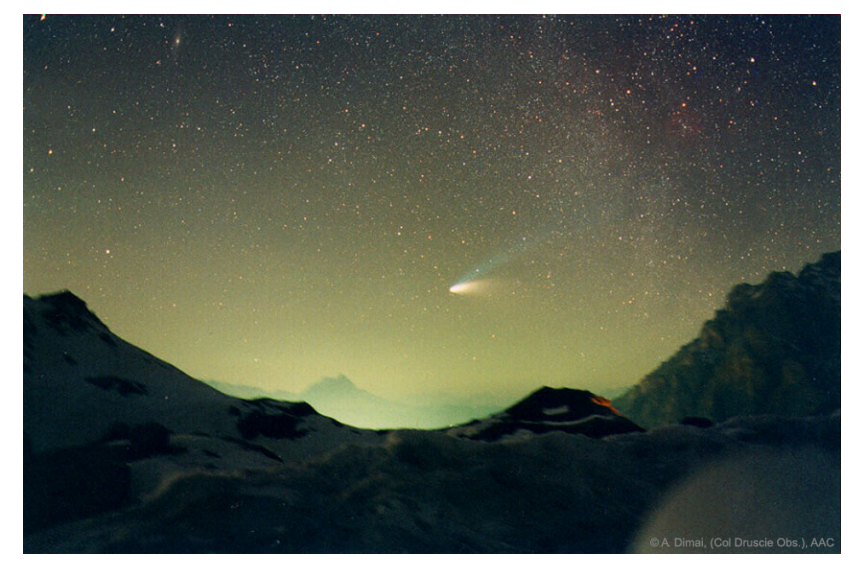

Figure 1. Comet Hale-Bopp over Valparola Pass (https://science. nasa.gov/comet-hale-bopp-over-val-parola-pass, last access: April 2021) (courtesy of Alessandro Dimai (Col Druscie Observatory), AAC).

The duration of visibility of the comet by Vital, some 50 nights, is generally consistent with the European observations, in which the comet was seen from November 1577 until early or mid-January of 1578 .

\section{Cultural background}

One aspect of the reports of the Great Comet of 1577 that has not been noted in prior publications is the likelihood of occurrence of an aurora on 13 November. Samuel Müller, in his tract on the comet, notes that on that date there was a "chasm" in the sky and that the sky was fiery and red while the comet lasted (Hellman, 1944:299). In the Late Medieval Period, under the influence of Aristotelian learning, the aurora was denoted by the Greek term chasmata (see, e.g., Silverman, 1962); Tycho also used this term in his meteorological notations from 1582 to 1597 (Brahe, 1876), initially writing it in the Greek and later as casmata or kasmata. Great auroras, and sometimes some at lesser activity, are generally red (see, e.g., Silverman, 2006; Hayakawa et al., 2019), consistent with the description of Müller. Auroral occurrence was at or near a minimum in 1577 (Silverman, 1992), though an aurora was reported on 18 December from Switzerland (Scheuchzer, 1752:82). Gemma had described two "chasms" occurring in 1575, probably aurora (Hellman, 1944:167), one of which was observed in the Netherlands in February (Hellman, 1944:182; Link, 1963:70-71). Thus it seems likely that the red color of 13 November 1577 was also an aurora.

Vital's cometary report is relatively straightforward, in comparison with the other contents in his Book of Visions, where Vital described dreams, omens, and their interpretations. Unlike the other sections, Vital simply described this comet itself without providing interpretations. Nevertheless, Vital probably regarded this great comet as an omen. According to Faierstein (1999:8), Vital had intended to move from
Safed to Jerusalem and interpreted this comet as an omen precipitating his move. In fact, he departed from Safed and started his travel for Jerusalem two weeks after viewing this great comet.

In parallel, an illustration of the European attitude towards comets at the time can be seen in the title page of Laurence Johnson's contemporary description of the 1577 comet (Johnson, 1578) (Fig. 2). The translation of the Latin ${ }^{2}$ title is as follows: "A certain cometography of a light in the air that appeared on 10 November, from the year of the virgin birth [i.e. AD, or CE] 1577." Herrmann translates the Latin at the bottom of the page as follows, "As the rainbow is a sign that the lands perished beneath the waters, so the fire [understood: of the comet is a sign] that all things will perish [fall, end] in their own fires" and adds the following context: "The inscription is in metered verse. The rainbow reference, of course, is to Genesis. But I can find no source for the fire reference. It may be original. A friend notes that in the Christian Testament the letter of II Peter 3:10 states the following: 'and the elements will be dissolved with fire' (RSV) ${ }^{3}$. Maybe Jewish texts have a similar reference." It could have been a common belief that the world would end in fire (though, as Robert Frost notes, "some say in ice" (first printed in Harper's Magazine, December 1920)). The representation of the comet in the center of the page includes inscriptions in Hebrew. The core of the comet is symbolized by God, the Tetragrammaton being used. Emanating from the core is the tail, on which the Hebrew ${ }^{4}$ inscription may be translated as "I shall surely come in judgment".

Such interpretations, referring specifically to Jerusalem, can also be found throughout the descriptions cited by Hellman (1944). Brunfels, for example, specifically noted the comet observed in Jerusalem prior to the destruction of the temple, an omen which he attributes to the failure of the Jews to accept Jesus. Brunfels says the following (p. 300): "and because they continued in their ways, forty years later, he sent a comet, like a sword, which stood for a year over Jerusalem. And afterwards, the city was besieged and the temple burned, and many people perished by sword, hunger, and pestilence, and the rest were scattered in all lands". The comet as a predictor of the downfall of Jerusalem was also noted by Heerbrand (Hellman, 1944:264), Kreidweiss (Hell-

\footnotetext{
${ }^{2}$ We are indebted to Francis Herrmann of the Boston College Law School, personal communication, 13 March 2007, for the translations of the Latin texts on the title page. These, enclosed in parentheses, with comments, are taken verbatim from an email of Herrmann.

${ }^{3}$ According to the New Living Translation, its whole text reads "But the day of the Lord will come as unexpectedly as a thief. Then the heavens will pass away with a terrible noise, and the very elements themselves will disappear in fire, and the earth and everything on it will be found to deserve judgment".

${ }^{4}$ We are indebted for help with the Hebrew reading to Naomi Cohen, University of Haifa, personal communication, 2007 and to Larry Marin, personal communication, 27 February 2007.
} 


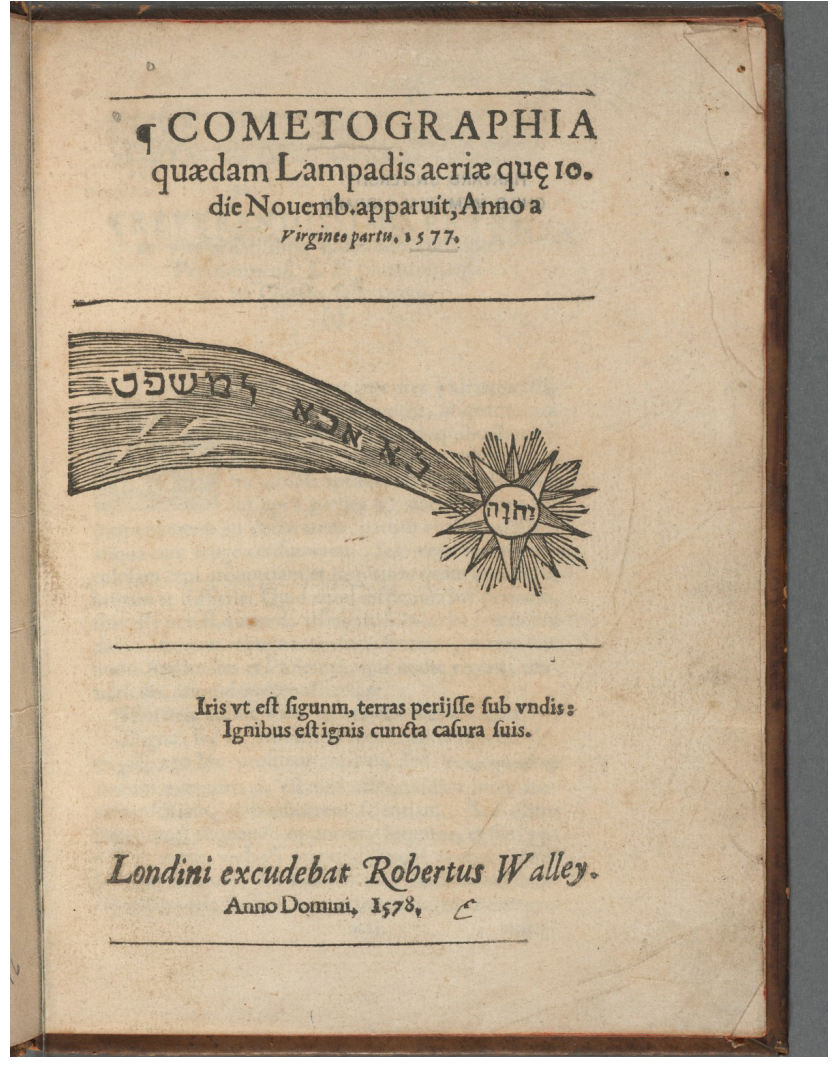

Figure 2. Title page of Laurence Johnson's contemporary description of the 1577 comet (Johnson, 1578) (courtesy of Harvard University, Houghton Library, call number: STC 1416).

man, 1944:265), Rocca (Hellman 1944:270), de Billy (Hellman, 1944:293), and Praetorius (Hellman, 1944:298).

The event was probably contextualized by Vital in the Jewish tradition, where comets had been associated with portents and omens. This tradition can be traced back even to Josephus, who described a great comet as a sword hanging over Jerusalem for almost a year and regarded this as a portent of the destruction of Jerusalem (Schechner, 1997:32). Similar episodes can be found in the Jewish culture throughout Schechner (1997). After all, comets had been considered a portent of multiple evils. Therefore, it is plausible that Vital wished just to note the event itself, being afraid of clarifying the possible interpretation of this great comet.

\section{Conclusions}

Here, we have consulted Chaim Vital's record for the 1577 Great Comet (C/1577 V1) and clarified its historical and cultural background. In his Book of Visions, Vital recorded the two-tailed comet at Safed in Palestine on the evening of 10 November 1577 . Gemma reported comet visibility for some 50 nights from November 1577 until early or midJanuary of 1578 . This visibility duration is consistent with contemporary cometary reports. Its description also resembles that of the auroral record on 13 November 1577, which was described as a "chasm" in the sky. This description has been typical in occidental medieval accounts as influenced by the Aristotelian cosmological scheme. Vital described this comet without interpretations, unlike the other records in his account. Analyses of contemporary accounts clarified that comets and aurorae had been associated with portents of multiple evils. Vital chose to note only the event itself, probably because comets had been considered evil omens, and he was possibly uneasy with examining its interpretations.

Data availability. No data sets were used in this article.

Author contributions. SMS authored this article in its entirety. EL edited the article for the publication process.

Competing interests. The authors declare that they have no conflict of interest.

Acknowledgements. We are indebted for helpful comments of Jon Huchra, Brian Marsden, Sara Schechner, and David Trilling. We thank Alessandro Dimai and Houghton Library, Harvard University (STC 1416), for providing images of Johnson's pamphlet and Comet Hale-Bopp over Valparola Pass.

Review statement. This paper was edited by Hisashi Hayakawa and reviewed by two anonymous referees.

\section{References}

Brahe, T.: Meteorologiske Dagbog, Kjøbenhavn: H.H. Thieles Bogtrykkeri, 1876.

Christianson, J. R.: Tycho Brahe's German treatise on the comet of 1577: A study in science and politics, Isis, 70, 110-140, 1979.

Faierstein, M. M.: Jewish Mystical Autobiographies: Book of Visions and Book of Secrets, New York, Mahwah, Paulist Press, 1999.

Granada, M. A.: Did Tycho eliminate the celestial spheres before 1586?, J. Hist. Astronomy, 37, 125-145, 2006.

Hayakawa, H., Mitsuma, Y., Fujiwara, Y., Kawamura, A. D., Kataoka, R., Ebihara, Y., Kosaka, S., Iwahashi, K., Tamazawa, H., and Isobe, H.: The earliest drawings of datable auroras and a two-tail comet from the Syriac Chronicle of Zūqnīn, Publ. Astron. Soc. Jpn., 69, 17, https://doi.org/10.1093/pasj/psw128, 2017.

Hayakawa, H., Ebihara, Y., Willis, D. M.; Toriumi, S., Iju, T., Hattori, K., Wild, M. N., Oliveira, D. M., Ermolli, I., Ribeiro, J. R., Correia, A. P., Ribeiro, A. I., and Knipp, D. J.: Temporal and Spatial Evolutions of a Large Sunspot Group and Great Auroral Storms Around the Carrington Event in 1859, Space Weather, 17, 1553-1569, https://doi.org/10.1029/2019SW002269, 2019. 
Hayakawa, H., Fujii, Y. I., Murata, K., Mitsuma, Y., Cheng, Y., Nogami, N., Ichikawa, K., Sano, H., Tsumura, K., Kawamoto, Y., and Nishino, M. N.: Three Case Reports on the Cometary Plasma Tail in the Historical Documents, J. Space Weather Spac., 11, 21, https://doi.org/10.1051/swsc/2020045, 2021.

Hellman, C. D.: The Comet of 1577: Its Place in the History of Astronomy, New York, Columbia University Press, 1944.

Johnson, L. fl. 1577: Cometographia quaedam lampadis aeriae que 10. die Novemb. apparuit, anno a Virginto partu, 1577, Londini, excudebat Robertus Walley, 1578.

Kronk, G. W.: Cometography: A Catalog of Comets, Volume 1, Ancient-1799, Cambridge University Press, 1999.

Link, F.: Observations et Catalogue des aurores boréales apparues en Occident de -626 à 1600, Geofysikální Sborník, X, 297-392, 1963.

Schechner Genuth, S.: Comets, Popular Culture, and the Birth of Modern Cosmology, Princeton, New Jersey, Princeton University Press, 1997.
Scheuchzer, J. J.: Natur-Historie des Schweizerlandes, Theil 3, Zürich, Heidegger und Comp, 1752.

Silverman, S. M.: On the "Chasms" of Aristotle and Pliny, J. Atm. Terr. Phys., 24, 1108-1109, 1962.

Silverman, S. M.: Secular variation of the aurora for the past 500 years, Rev. Geophys., 30, 333-351, 1992.

Silverman, S. M.: Comparison of the aurora of September 1/2, 1859 with other great auroras, Adv. Space Res., 38, 136-144, 2006.

Silverman, S. M.: Palestinian observations of the Comet of 1577, International Comet Quarterly, 30, 123-124, 2008.

Van Nouhuys, T.: The Age of Two-Faced Janus: The Comets of 1577 and 1618 and the Decline of the Aristotelian World View in the Netherlands, Leiden, Brill, 1998.

Zolotova, N., Sizonenko, Y., Vokhmyanin, M., and Veselovsky, I.: Indirect Solar Wind Measurements Using Archival Cometary Tail Observations, Solar Physics, 293, 85, https://doi.org/10.1007/s11207-018-1307-4, 2018. 